\title{
Tissue Engineering of Tendons
}

\author{
Johanna Buschmann
}

Additional information is available at the end of the chapter

http://dx.doi.org/10.5772/intechopen.73507

\begin{abstract}
Critical size tendon defects demand for tissue samples replacing the missing tissue and guiding an effective healing. Autografts, allografts, or xenografts represent viable options; however, limited availability and donor site morbidity go along with this approach, representing big disadvantages. Tissue engineering of tendon tissue is a further strategy fulfilling this need. Basically, an appropriate scaffold material is developed and tested for its biomechanical suitability as a graft material. In addition, cell seeding might improve biointegration of the tissue engineered construct (TEC). Different cell sources as well as different cultivation procedures can be applied in order to tune the envisioned primary strength of the TEC. In this chapter, in vitro fabrication protocols and mechanical tests as well as animal in vivo experiments will be presented-covering various (bio)materials, cell types, and cultivation procedures.
\end{abstract}

Keywords: tendon, graft, scaffold, biomechanics, gene therapy, growth factor

\section{Introduction}

Tendon injuries as encountered by accidents may end up in complete ruptures, going along with tissue defects that have to be replaced with the aim to regain full function-without pain. In order to offer the body suitable substitutes for what it has lost, materials are needed that guide and stimulate the healing process and finally lead to a fully integrated and sufficiently stable tissue. Main problems occurring after tendon rupture repairs are insufficient strength (leading probably to re-ruptures) and adhesion formation (leading to a diminished range of motion) [1].

Best grafts for the reconstruction of injured tendons are obviously tendons themselves, however, although sometimes possible, tendon grafts are very limited in terms of availability and have to be decellularized before application if they are allografts or even xenografts to avoid 
transplant rejections. Only autografts are easily transplanted-but the donor site morbidity may cause a lot of pain and go along with impaired function. In addition, other disadvantages of autografts are reported to be insufficient strength [2] because other tendons than the one to be replaced might be different in strength, cellularity as well as gliding capacity [3].

Hence, an excellent alternative to decellularized tendons is the tissue engineered construct (TEC) aimed to be attached to tendon stumps [4] (Figure 1). In this field, tissue engineering has covered natural materials like collagen constructs [5], combinations of natural and synthetic components as realized in PLGA and alginate [6] or entirely synthetic polymers such as PCL \pm PEO [7]. Many reports on seeding cells onto the corresponding materials have determined their impact, including extracellular matrix deposition and inherently going along changes in stability [8]. Other strategies include growth factors implemented in the graft material $[9,10]$ with the ultimate aim to be released sustainably to the repair site in order to support and accelerate the innate healing process [11].

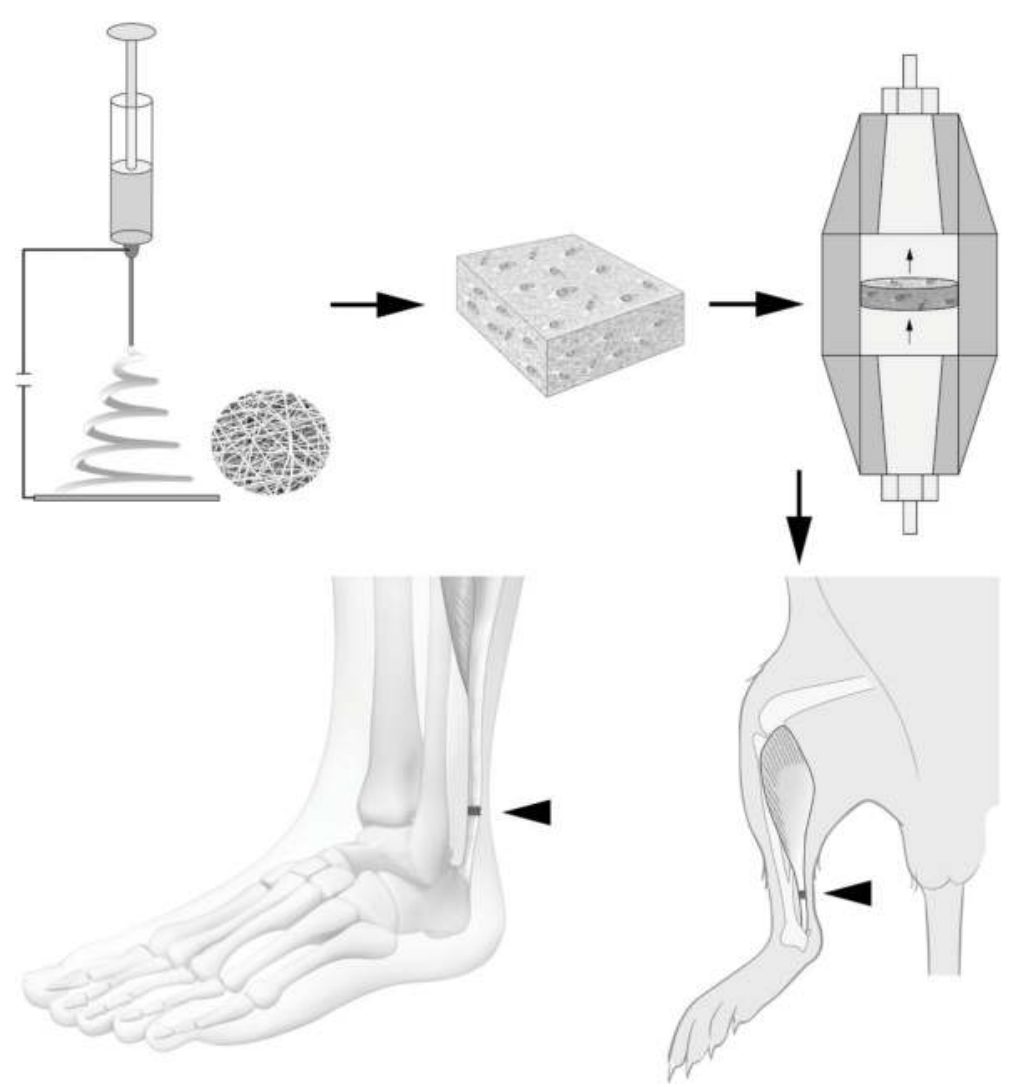

Figure 1. Fabrication of a tissue engineered construct. As a first step, a scaffold material is used and processed as exemplified by electrospinning. Then, cells may be seeded onto the construct. After that, the cell-seeded construct may be cultivated under static conditions or under perfusion in a bioreactor before being implanted into an appropriate animal model. As a final step, performance of the TEC is assessed in a clinical trial. 
In this chapter, natural and synthetic materials as well as combinations of them are presented. Moreover, different types of cells seeded onto TECs are compared and their performance in vitro and in vivo [12] are discussed in a step-by-step manner with criteria set as evaluation milestones [13]. Although many of these approaches are highly promising in animal studies, they did not yet find their ways into clinical application because the success of new graft materials is finally dictated by clinical outcomes of studies where graft materials are implanted into the human body - and clinical trials are not only expensive, they also take a long time to be performed. Tissue engineered constructs that were developed 10 years ago might only now be ready to be judged and tested in terms of clinical success or failure.

\section{Native tendons}

\subsection{Structure and composition of tendons}

Before we turn our interest toward tissue engineering of tendons, a brief summary of what native healthy tendon tissue is composed of and of the characteristics of human and selected animal tendons is given here. The hierarchical structure of the tendon tissue is very well-known and has been characterized by multiple imaging and analysis techniques [14]. Starting with the smallest molecular entity, tropocollagen molecules assemble to form microfibrils. Covalently connected, these microfibrils form sub-fibrils and fibrils of the collagen which is typically seen in histological sections of tendon tissue as slightly waved "crimps" [15, 16]. Fibrils form bundles resulting in fascicles. Between the fascicles, there are cell-rich layers called endotenons that can be very well seen in histological sections, as the tenocytes form "lines," one behind each other connected by gap junctions that are important for mechanotransduction [17-19].

In addition, there are some tendons that have a peritenon around the whole tendon. The peritenon is a thin sheath around the tendon, but should not be confused with the tendon sheath on intrasynovial tendons [20]. More information on the organization of the tendon tissue are found in several articles [14, 21, 22], with a special emphasis on the extracellular matrix (ECM) [23].

In the ECM, the main component is collagen I (around 95\% of the dry weight). The noncollagenous part of tendons is composed of proteoglycans like lubricin, decorin or biglycan, glycosaminoglycans (GAGs; typically encountered as chondroitin sulfate, dermatan sulfate or heparan sulfate) and glycoproteins such as fibronectin. Proteoglycans are important for tissue hydration (especially decorin) and it was found that they are essential for limiting the viscoelastic behavior by preventing tissue fatigue [24]. When GAGs of an extracted fascicle were enzymatically digested, they exhibited higher reductions in failure stress and more stress relaxation, supporting the regulation of viscoelasticity [24]. Noteworthy, water makes up $60-80 \mathrm{wt} \%$ of the entire tendon tissue and is - together with the GAGs - a highly important component regulating viscoelasticity [25]. Moreover, elastin has not to be neglected although it makes up only $2 \%$ of the tendon dry weight. Elastin fibers are found closely to the tenocytesthe cells in the tendon tissue [26].

Tenocytes are the mature tendon cells, while tenoblasts are the immature ones. Tenoblasts build up the ECM components. They are spindle-shaped, very similar to fibroblasts - and their 
morphology changes upon aging [27] and mechanical loading [28]. Surface marker characterization of tenocytes and tenoblasts includes tenomodulin [29], which is induced by scleraxis (Scx), a transcription factor identifying tendon cells during development [30]. Other cell types occurring in tendon are synovial cells, typically found in the tendon sheath and synovial lining cells. One subtype of synovial lining cells produces hyaluronic acid, an important lubricant facilitating the gliding of the tendon in the sheath [31]. In addition, tendons do also have stem cells, primarily residing in a niche composed of biglycan and fibromodulin [32]. Like other adult stem cells, tendon stem cells are able to self-renew, form colonies, and differentiate into lineages like osteoblasts, chondrocytes, or adipocytes [33, 34].

\subsection{Biomechanical baseline values}

For successful tissue engineering of tendons, it is essential to know the basic mechanical properties of the tendons that have to be reconstructed in order to plan processing steps accordingly. Hence, ex vivo determined biomechanical properties of target tendons are crucial and should always be taken as background information to compare (a) in vitro mechanical properties of TECs and (b) in vivo mechanical properties of TECs [13]. Tendon ultimate stress values of all human tendons are in a range of approximately 5-80 MPa. Supraspinati of the shoulder exhibit quite weak tendon tissue in the posterior portion with only $4 \pm 1 \mathrm{MPa}$ [35], while Achilles tendons have ultimate stresses of $79 \pm 22 \mathrm{MPa}$ [36].

The age influences the stability of the tendon tissue; while Achilles tendons of old people aged 79-100 years were reported to have ultimate stresses of $48 \pm 16 \mathrm{MPa}$, younger people (3650 years old) had corresponding values of $73 \pm 8 \mathrm{MPa}$; interestingly, an age group in between 52 and 67 years had the strongest Achilles tendons with $81 \pm 14 \mathrm{MPa}$ [37]. Besides age, also gender plays a significant role when mechanical properties of tendons are assessed and compared; female donors usually have weaker tendons and ligaments than male donors [38], however, weaker and softer Achilles tendons of women compared to men might also be a consequence of different levels of exercise-and therefore cannot only be attributed to gender [39].

Besides these intrinsic factors (age and gender), physical activity also plays an important role and has a major impact on tendon strength and elasticity. As a consequence, surgical intervention at a ruptured tendon of an athlete might need a different graft material compared to a ruptured tendon of a person that does not do any exercise beyond daily low-impact activities. Interestingly, also exercise in elderly people has a massive impact on tendon strength and elasticity. In a study performed with two groups of elderly people [aged $74 \pm 5$ years $(n=9)$ for group 1 and group 2 had and age of $68 \pm 6$ years $(n=8)$ ], significant impact on the stiffness and elastic modulus of the patellar tendon was found when assessed by ultrasound measurements. Group 1 did one lesson of exercise per week going only to $40 \%$ of their maximum capacity, while group 2 had two lessons weekly and went to $80 \%$ of their highest capacity. As a result 12 weeks later, the elasticity of the tendons in group one was not changed, while group 2 had 1.6-fold increased stiffness and 1.5-fold increased elastic modulus [40]. Hence, intrinsic factors should not be interpreted alone; however, extrinsic factors like exercise and other physical activities should be considered too.

Compared to humans, the animal realm covers a wider range of mechanical properties; from rat tendons to horse tendons, there is a span of one order of magnitude in ultimate stress; with horse flexor digitorum superficialis having values of $109 \pm 8 \mathrm{MPa}$ [41], while rat Achilles tendons 
only have ultimate stresses of $16 \pm 6 \mathrm{MPa}$ [42]. In terms of elasticity, the range for animals is also larger than for humans. While for human tendons it is up to around $800 \mathrm{MPa}$, for animals, values 1.5 times as high are found like for the rabbit flexor digitorum profundus which has an elastic modulus of $1166 \pm 281$ [43] or the horse flexor digitorum superficialis with a modulus of $1189 \pm 63 \mathrm{MPa}$ [44]. Xenografts, although rejection problems may arise, might nevertheless be useful starting points if refinements by cell seeding or other cues manipulating the graft are applied too. Otherwise, tendon tissue engineering intended at veterinary clinical application should include such baseline values when planning to fabricate appropriate TECs.

\section{Natural materials}

\subsection{Collagen}

Tendon tissue basically consists of type I collagen [14, 45]. Therefore, many approaches in tendon tissue engineering take collagen as a material in order to fabricate appropriate TECs [46]. It has to be noted that mechanical properties of collagen greatly depend on the processing. Kumar and co-workers produced robust planar collagen fiber constructs by drying collagen gels to form dense collagen mats that were layered [47]. With this approach, they were able to tune ultimate stress values between 0.6 and $1.8 \mathrm{MPa}$; if they used an additional crosslinking step, the range of ultimate stress increased to 4.7 up to $10.5 \mathrm{MPa}$ [47]. As for the elastic modulus, not cross-linked collagen mats exhibited elastic moduli of 2.0-6.3 MPa; with crosslinking, however, such fabricated mats had moduli of 52-114 MPa [47]. Obviously, with only one processing step (crosslinking), mechanical characteristics could be changed by an order of magnitude, enabling the tissue engineer to adapt his material to the mechanics envisioned.

Also, commercially available collagen scaffolds show a wide range of mechanical properties and may be chosen upon those selection criteria [48]. Generally, such scaffolds are patches that are used as augmentations in order to increase the primary repair strength after operation. The following commercially available collagen patches are described further in [48]. They are presented with decreasing strength (Table 1).

\begin{tabular}{lll}
\hline Trade name & Tissue & Ultimate load (N) \\
\hline GraftJacket $^{\circledR}$ extr. 2.0 & Human dermis & $229 \pm 72$ \\
MaxForce $^{\circledR} 1.4$ & Human dermis & $182 \pm 50$ \\
GraftJacket $^{\circledR} 1.0$ & Human dermis & $157 \pm 38$ \\
Permacol $^{\circledR} 1.0$ & Porcine dermis & $128 \pm 26$ \\
TissueMend $^{\circledR} 1.1$ & Fetal bovine dermis & $76 \pm 22$ \\
TissueMend $^{\circledR} 1.2$ & Fetal bovine dermis & $70 \pm 13$ \\
Restore $^{\circledR} 1.0$ & Porcine small intestinal submucosa & $38 \pm 3$ \\
CuffPatch $^{\circledR} 1.0$ & Porcine small intestinal submucosa & $32 \pm 4$ \\
\hline
\end{tabular}

Table 1. Selected commercially available collagen scaffolds sold as patches for tendon or ligament augmentation in the order of decreasing strength according to [48]. 
Depending on the processing technique and the final architecture and structure of the collagen scaffold, ultimate stress and elastic modulus vary over a range of six orders of magnitudes, with the following increasing order:

sponges $<$ gels $<$ yarns, mats $<$ cross-linked mats $<$ cross-linked yarns $<3$ D extruded fibers

As shown by Kato and colleagues, extruded collagen fibers highly resemble mechanical characteristics of rat tail tendon tissue [49], with elastic moduli >1000 MPa and ultimate stress $>600 \mathrm{MPa}$. However, these mechanical assessments were made under dry conditions. As tendons are hydrated tissues, wet conditions should rather be taken into account. For that reason, Zeugolis et al. compared extruded collagen fibers under wet and dry conditions and found that wet extruded fibers were swelling (increase in CSA), while ultimate stress values decreased by factors up to 2000 [50]. Therefore, other optimization strategies like blending collagen with PEG (polyethylene glycol) were undertaken in order to achieve not only the desired fiber thickness but also envisioned mechanical properties [51]. Moreover, crosslinking of extruded collagen fibers with different chemical agents like aldehydes and isocyanates, biologically by microbial transglutaminase or physically by photo-oxidation was compared in terms of fiber diameter and mechanical properties [52]. A total of 16 different ways for crosslinking were compared and the high variability in characteristics was summarized [52].

\subsection{Silk}

Silk is derived from silkworm cocoons named Bombyx mori (mulberry silk) consisting of two fibroin proteins, and has been approved by the Food and Drug Administration [53]. The physical properties of silk fibroin (which is achieved after sericin is removed) are ideal for tendon grafts. Moreover, silk fibroin is biodegradable and compatible and can also be structurally changed and adapted for different purposes [54]. Silk fibroin exhibits ultimate stress values up to $4800 \mathrm{MPa}$, which is far beyond maximum ultimate stress limits of human tendons (approximately $80 \mathrm{MPa}$ ) and animal tendons (around $120 \mathrm{MPa}$ ). Physical properties can be tuned by giving the silk fibroin different architectures. Li and Snedeker showed that wired, braided, and straight silk fibroin fibers behaved differently in biomechanical fatigue tests [55]. They found that a wired structure best fitted their final target which was an anterior cruciate ligament. In addition, also knitted silk fibroin gained from a non-mulberry silk intended at tendon tissue engineering has been tested in vitro, and Musson and co-workers found that cell attachment and growth was satisfactory [56]. Finally, biphasic silk fibroin scaffolds with different pore alignments (anisotropic and isotropic) mimicking the tendon-bone interface are very promising TECs based on this natural material [57].

Often, silk is combined with other materials like collagen [58, 59], PDLLA [60], or PLGA [61, 62] in order to manipulate and adapt the TEC under view. As a promising example, silk fibroin was combined with PCL and electrospun nanofibers of this blend were seeded with rabbit dermal fibroblasts, with the result that silk fibroin favored and supported cell proliferation compared to blank PCL and tendon-specific proteins like collagen and tenascin-C were increased and deposited to a higher amount in an in vivo experiment using New Zealand White rabbits and an Achilles tendon partial defect [63]. Moreover, also biomechanics were 
considerably enhanced by the presence of silk fibroin in this blend compared to mere PCL [63] because silk is a very stress-resistant material and can be tuned so well in order to cover a wide range of mechanical properties; it has not only been considered for tissue engineering of tendons but also for applications in bone tissue engineering [64-67].

\subsection{Chitosan}

Chitin and its derivative chitosan are getting more and more attractive as a suitable natural biomaterial for tissue engineering purposes [68], especially for tendons [69]. In a combination with poly acrylic acid, composite films were fabricated by a layer-by-layer technique. These films exhibited elastic moduli of $27-420 \mathrm{kPa}$ suitable for tissue engineering of tendons exhibiting low elastic moduli [70]. Other composites like chitosan-hyaluronic acid were used to close defects of infraspinatus in a rabbit model. The result was that ultimate stress and elastic modulus were significantly increased as compared to defects closed without this scaffold [71]. Moreover, the same composite material was also used for medial collateral ligament reconstruction in a rabbit model and it was found to be a promising substitute in case cells were seeded on the chitosan-hyaluronan [72].

Chitosan in combination with collagen has also been investigated to serve as a material for tissue engineering: addition of chitosan to bovine and salmon collagen scaffolds improved the mechanical properties by increasing the compressive strength and the swelling ratio [73]. Moreover, a rat Achilles tendon study, where a scaffold based on chitosan- $\beta$-glycerophosphate-collagen was used, demonstrated the effectiveness of this composite material for this purpose [74].

\section{Synthetic materials}

If synthetic polymers are used for (tendon) tissue engineering, the fabrication process highly decides upon its biocompatibility and its effectiveness as graft. As nicely shown by Prof. Ratner, the same polymer, once applied as a porous foam and once as a dense block, can evoke quite different reactions of the body: while the porous material is penetrated by ingrowing cells as well as vasculature and there is practically no foreign body reaction, the dense block is encapsulated as a foreign body going along with an inflammation reaction [75] - in vivo veritas [76]. Hence, the processing of a synthetic material, mostly polymers in tendon tissue engineering, has to be optimized in order to get a biocompatible material that fulfills the requirements encountered in tendon tissue engineering.

Many polymers have been synthesized and modified in order to get suitable materials in terms of implants for tendon repair and regeneration; polyglycolic acid (PGA) [75, 77], polylactic-co-glycolic acid (PLGA) [78], PLGA/alginate composite [6], polylactic acid (PLA) [79-81], poly-L-lactic acid (PLLA) [82-84], polycaprolactone (PCL) [85], polycaprolactone/ polyethylene oxide (PCL/PEO) [7], polyurethane (PU) [86, 87], polyethylene terephthalate (PET) [88, 89], DegraPol ${ }^{\circledR}[90,91]$ (Figure 2), nanocarbon fiber [92], and polyurea [93], among others. The architecture of the synthetic materials has to be chosen carefully, as gene expression of (stem) cells may be significantly influenced by the microenvironment that the cells encounter [94]. 

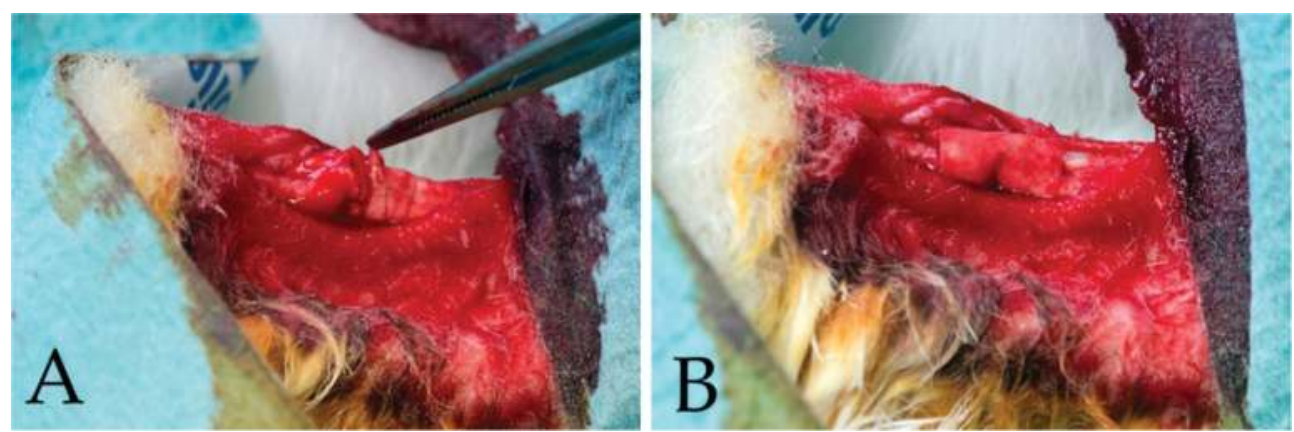

Figure 2. Application of DegraPol ${ }^{\circledR}$. An electrospun $\mathrm{DegraPol}^{\circledR}$ tube is placed around a fully transected rabbit Achilles tendon (A) in order to deliver a growth factor to the repair site. The laceration is sutured by a 4-strand Becker suture and the tube is pulled over $(\mathrm{B})$.

\section{Cellular approaches}

The potential of stem cells for regenerative medicine and for tissue engineering applications has been reported many times with convincing evidence in vitro and in vivo and comprehensive information given in recent review articles $[12,95]$. Hence, although tenocytes would be the first and self-evident cell source to be used in tendon tissue engineering [20,96,97], there are more reports based on stem cells for the same purpose. For example, adipose-derived stem cells were seeded onto biphasic silk scaffold in order to fabricate a tendon-to-bone interface, mimicking the gradient-like structure of the enthesis [57]. Adipose-derived stem cells are easily harvested and differentiated toward a desired lineage [98] and amounts per gram of tissue are higher as compared to other stem cells sources like bone marrow [99]. Hence, these cells are very well suited for tissue engineering purposes, like tendon tissue engineering [100, 101]. Among different stem cell sources, however, the best source of stem cells for tendon tissue engineering is reported to be tendon stem cells, although their availability is limited and the harvesting protocol everything else than easy [32]. An interesting study reports the beneficial effect of seeding tendon-derived stem cells onto a chitosan- $\beta$-glycerophosphate-collagen hydrogel scaffold intended to repair an Achilles tendon defect in a rat model [74]. The healing was enhanced as indicated by the improvement in histological and immunohistochemical outcomes. In addition, the increase in the biomechanical properties of the regenerated tissue at both 4 and 6 weeks post-operation also supported the effectiveness of tendon-derived stem cells [74].

The in vitro preparation of cell-based TECs highly determines the mechanical properties; cellseeded scaffolds cultivated under static conditions have different characteristics compared to TECs cultivated under dynamic conditions - as for example cultivation in a bioreactor with medium perfusion flow and/or tensile stretching/compression regimen [102]. Collagen sponges seeded with MSCs have been reported to have significantly higher mechanical properties when cultivated with mechanical stimulation than under static conditions [103]. Also, the expression of collagen I and III are increased upon mechanical stimulation, as shown for rabbit MSC/collagen sponges and murine MSC/collagen sponges [104]. In such approaches of 
dynamic cell culture and cell-seeded TECs, physical experimental parameters like frequency, amplitude, medium flow rate, etc., have to be carefully tuned in order to get the desired differentiation (if stem cell-based) and the intended biomechanics [105-108].

Other concepts in tendon tissue engineering are based on decellularization of a natural xenograft in order to avoid immunorejection [4, 109-111] or decellularization of a primarily cellseeded construct in order to generate a scaffold coated with the components of the ECM of a certain cell type (instructive ECM) cultivated under well-defined conditions [112, 113]. Such decellularized graft materials can be applied in daily clinical practice more easily than cellseeded TECs; because storage is facilitated without (living) cells [114].

Furthermore, there are gene therapy strategies including adeno-associated viral type 2 vector (AAV2) and micro-RNA related gene therapy aiming at improving strength of the repaired tendon as well as decreasing adhesion formation to the surrounding tissue [115, 116]. Moreover, some approaches deal with delivering certain (growth) factors, supporting the regeneration process of tendons $[117,118]$.

TGF- $\beta 1$ plays an important role during tendon healing and has an influence on adhesion formation, an unwanted side effect during tendon healing. Therefore, regulation of TGF- $\beta 1$ through application of micro-RNA specifically inhibiting the function of TGF- $\beta 1$ was tested in a chicken flexor tendon model [119]; TGF- $\beta$ protein expression in the tendons decreased on increasing the vector dosage. As a consequence, the adhesion extent significantly decreased 6 and 8 weeks post-injury; however, tendon strength unfortunately was also reduced [119]. Another study showed that gene therapy to produce supernormal amounts of bFGF or VEGF supported the intrinsic tendon healing in a chicken flexor tendon model-with a significantly higher tendon strength by $68-91 \%$ from week 2 after AAV2-bFGF treatment and by $82-210 \%$ from week 3 after AAV2-VEGF compared to controls [120]. At the same time, adhesion formation was not adversely affected.

Because decorin and IL-10 downregulate TGF- $\beta 1$, another approach included co-delivery of decorin and IL-10 transgenes from a collagen hydrogel system to a tenocyte culture in vitro. As expected, TGF- $\beta 1$ was downregulated and simultaneously also collagen I and III and fibronectin. The authors concluded that this approach might be a useful tool against scar formation (extensive fibrosis), the system has not yet been tested in vivo, however [121]. Moreover, another AAV-based approach was the delivery of VEGF to chicken flexor tendons; after complete transection of these tendons, $2 \times 10^{9}$ particles of AAV2-VEGF or saline (as control) were injected before they were surgically repaired [122]. The outcome was a significantly increased ultimate strength 4, 6 and 8 weeks post-operation, while the adhesion was unaffected [122]. Hence, such gene therapy approaches might get more significance also in daily clinical life, as they are easily performed (injection of a small volume only) and show promising effects.

Another nice example has been shown using Scx-transduced tendon-derived stem cells in a rat unilateral patellar tendon window injury model. For transplantation, a TEC based on fibrin and transduced cells was used. Tendon repair was significantly improved in terms of histology and biomechanics in vivo. In vitro results showed that Scx-transduced tendonderived stem cells expressed tendon- and also cartilage-related genes to a higher level; as for 
osteogenic markers (which might be regarded as an unwanted differentiation), the results remained inconclusive [123]. Further reports on gene therapy dealing with the tendon-togone interface also used BMPs [124].

\section{Drugs to stimulate the healing}

Growth factors or drugs aiming at the support of the healing process can be injected directly to the wound site. However, one major problem encountered by doing that is that activity of such biological molecules (often proteins) is short-lived. Hence, a suitable strategy is to take a delivery device realized by an implant material or a TEC allowing sustained release of the drug to the repair site over longer periods of time. Among many others, one interesting growth factor supporting tendon rupture repair is PDGF-BB [125]. It is not only mitogenic but also angiogenic and chemotactic-ending up in accelerated cell proliferation, migration, increased collagen synthesis and vascularity, and finally improved biomechanics of the repaired tendon [125]. Hence, a random-fiber electrospun delivery device in form of a tube was developed which not only allowed the controlled release of PDGF-BB [11], but also acted as an effective physical anti-adhesion barrier [126]. Without the growth factor included, this TEC neither evokes any adverse cellular effects nor influences inflammation reaction toward the implant $[90,91]$. With the growth factor, biomechanics improved significantly, underlying promising perspectives for this bioactive implant.

Another approach using tendon-derived progenitor/stem cells seeded onto an aligned randomfiber mesh made of PLLA discovered that tenogenesis of these stem cells was not triggered by the aligned fibers, which was previously hypothesized. Because the expression of histone deacetylases was found to be reduced in the progenitor cells seeded on the aligned fibers, a small molecule (Trichostatin A), which is an inhibitor of histone deacetylases, was incorporated in the aligned fiber mesh. As a result of this bioactive mesh, the corresponding progenitor cells seeded on this TEC showed better tenogenesis and when implanted in a rat Achilles tendon model, the healing was accelerated and improved compared to non-Trichostatin TECs [83].

\section{Conclusion}

Tissue engineering of tendon substitutes and grafts is a viable option to close critical size defects. The choice of a suitable scaffold material, natural or synthetic, is a decision which should be based on biomechanical baseline values of native tendon tissues and which will direct/affect biocompatibility, cell attachment, or incorporation of factors that support the healing process. Cell seeding and cultivation may be performed under static conditions as well as in dynamic systems using bioreactors. Bioreactors offer perfusion flow resulting in shear stress; additional mechanical stimulation by stretching the cell-seeded TEC may help to improve the mechanical characteristics of the TEC and trigger the desired differentiation if stem cells are involved. Growth factors incorporated in TECs may also support the healing process of the lacerated tendon tissue. 


\section{Author details}

Johanna Buschmann

Address all correspondence to: johanna.buschmann@usz.ch

Plastic Surgery and Hand Surgery, Department of Surgical Research, University Hospital Zurich, Switzerland

\section{References}

[1] Elliot D, Giesen T. Primary flexor tendon surgery: The search for a perfect result. Hand Clinics. 2013;29:191-206. DOI: 10.1016/j.hcl.2013.03.001

[2] Vališ P, Sklenský J, Repko M, Rouchal M, Novák J, Otaševič T. Most frequent causes of autologous graft failure in anterior cruciate ligament replacement. Acta Chirurgiae Orthopaedicae et Traumatologiae Cechoslovaca. 2014;81:371-379

[3] Karabekmez F, Zhao C. Surface treatment of flexor tendon autograft and allograft decreases adhesion without an effect of graft cellularity: A pilot study. Clinical Orthopaedics and Related Research®. 2012;470:2522-2527. DOI: 10.1007/s11999-012-2437-x

[4] Lui H, Vaquette C, Bindra R. Tissue engineering in hand and surgery: A technology update. Journal of Hand Surgery-American Volume. 2017;42:727-735. DOI: 10.1016/j.jhsa.2017.06.014

[5] Juncosa-Melvin N, Boivin GP, Gooch C, Galloway MT, West JR, Dunn MG, et al. The effect of autologous mesenchymal stem cells on the biomechanics and histology of gelcollagen sponge constructs used for rabbit patellar tendon repair. Tissue Engineering. 2006;12:369-379

[6] Vaquette C, Slimani S, Kahn CJ, Tran N, Rahouadj R, Wang X. A poly(lactic-co-glycolic acid) knitted scaffold for tendon tissue engineering: An in vitro and in vivo study. Journal of Biomaterials Science. Polymer Edition. 2010;21:1737-1760. DOI: 10.1163/092050609x12 560455246676

[7] Beason DP, Connizzo BK, Dourte LM, Mauck RL, Soslowsky LJ, Steinberg DR, et al. Fiberaligned polymer scaffolds for rotator cuff repair in a rat model. Journal of Shoulder and Elbow Surgery/American Shoulder and Elbow Surgeons. 2012;21:245-250. DOI: 10.1016/j. jse.2011.10.021

[8] Pietschmann MF, Frankewycz B, Schmitz P, Docheva D, Sievers B, Jansson V, et al. Comparison of tenocytes and mesenchymal stem cells seeded on biodegradable scaffolds in a full-size tendon defect model. Journal of Materials Science-Materials in Medicine. 2013;24:211-220. DOI: 10.1007/s10856-012-4791-3

[9] Dines JS, Weber L, Razzano P, Prajapati R, Timmer M, Bowman S, et al. The effect of growth differentiation factor-5-coated sutures on tendon repair in a rat model. Journal of Shoulder and Elbow Surgery. 2007;16:S215-SS21. DOI: 10.1016/j.jse.2007.03.001 
[10] Paredes JJ, Andarawis-Puri N. Therapeutics for tendon regeneration: A multidisciplinary review of tendon research for improved healing. In: Sun HB, editor. Musculoskeletal Repair and Regeneration. 2016. pp. 125-138. DOI: 10.1111/nyas.13228

[11] Evrova O, Houska J, Welti M, Bonavoglia E, Calcagni M, Giovanoli P, et al. Bioactive, elastic, and biodegradable emulsion electrospun DegraPol tube delivering PDGF-BB for tendon rupture repair. Macromolecular Bioscience. 2016;16:1048-1063. DOI: 10.1002/mabi. 201500455

[12] Leong DJ, Sun HB. Mesenchymal stem cells in tendon repair and regeneration: Basic understanding and translational challenges. In: Sun HB, editor. Musculoskeletal Repair and Regeneration. 2016. pp. 88-96. DOI: 10.1111/nyas.13262

[13] Shearn JT, KRC K, Dyment NA, Galloway MT, Kenter K, Wylie C, et al. Tendon tissue engineering: Progress, challenges, and translation to the clinic. Journal of Musculoskeletal \& Neuronal Interactions. 2011;11:163-173

[14] Sharma P, Maffulli N. Biology of tendon injury: Healing, modeling and remodeling. Journal of Musculoskeletal Neuronal Interactions. 2006;6:181-190

[15] Kahn CJF, Dumas D, Arab-Tehrany E, Marie V, Tran N, Wang X, et al. Structural and mechanical multi-scale characterization of white New-Zealand rabbit Achilles tendon. Journal of the Mechanical Behavior of Biomedical Materials. 2013;26:81-89. DOI: 10.1016/j.jmbbm.2013.05.028

[16] Buschmann J, Puippe G, Meier Buergisser G, Bonavoglia E, Giovanoli P, Calcagni M. Correspondence of high-frequency ultrasound and histomorphometry of healing rabbit Achilles tendon tissue. Connective Tissue Research. 2014;55:123-131. DOI: 10.3109/ 03008207.2013.870162

[17] Andarawis-Puri N, Flatow EL, Soslowsky LJ. Tendon basic science: Development, repair, regeneration, and healing. Journal of Orthopaedic Research. 2015;33:780-784. DOI: 10.1002/ jor.22869

[18] Wang JHC. Mechanobiology of tendon. Journal of Biomechanics. 2006;39:1563-1582. DOI: 10.1016/j.jbiomech.2005.05.011

[19] JHC W, Thampatty BP. An introductory review of cell mechanobiology. Biomechanics and Modeling in Mechanobiology. 2006;5:1-16. DOI: 10.1007/s10237-005-0012-z

[20] Cadby JA, Buehler E, Godbout C, van Weeren PR, Snedeker JG. Differences between the cell populations from the Peritenon and the tendon Core with regard to their potential implication in tendon repair. PLoS One. 2014;9. DOI: 10.1371/journal.pone.0092474

[21] Silver FH, Freeman JW, Seehra GP. Collagen self-assembly and the development of tendon mechanical properties. Journal of Biomechanics. 2003;36:1529-1553. DOI: 10.1016/ S0021-9290(03)00135-0

[22] Killian ML, Cavinatto L, Galatz LM, Thomopoulos S. The role of mechanobiology in tendon healing. Journal of Shoulder and Elbow Surgery. 2012;21:228-237. DOI: 10.1016/j. jse.2011.11.002 
[23] Screen HRC, Berk DE, Kadler KE, Ramirez F, Young MF. Tendon functional extracellular matrix. Journal of Orthopaedic Research. 2015;33:793-799. DOI: 10.1002/jor.22818

[24] Legerlotz K, Riley GP, Screen HRC. GAG depletion increases the stress-relaxation response of tendon fascicles, but does not influence recovery. Acta Biomaterialia. 2013; 9(6):6860. DOI: 10.1016/j.actbio.2013.02.028

[25] Wellen J, Helmer KG, Grigg P, Sotak CH. Spatial characterization of T1 and T2 relaxation times and the water apparent diffusion coefficient in rabbit Achilles tendon subjected to tensile loading. Magnetic Resonance in Medicine. 2005;53:535-544. DOI: 10.1002/mrm.20361

[26] Grant TM, Thompson MS, Urban J, Yu J. Elastic fibres are broadly distributed in tendon and highly localized around tenocytes. Journal of Anatomy. 2013;222:573-579. DOI: 10.1111/joa.12048

[27] Nourissat G, Houard X, Sellam J, Duprez D, Berenbaum F. Use of autologous growth factors in aging tendon and chronic tendinopathy. Frontiers in Bioscience. 2013;E5:911-921

[28] Abraham T, Fong G, Scott A. Second harmonic generation analysis of early Achilles tendinosis in response to in vivo mechanical loading. BMC Musculoskeletal Disorders. 2011;12:26. DOI: 10.1186/1471-2474-12-26

[29] Docheva D, Hunziker EB, Fassler R, Brandau O. Tenomodulin is necessary for tenocyte proliferation and tendon maturation. Molecular and Cellular Biology. 2005;25:699-705. DOI: $10.1128 / \mathrm{mcb} .25 .2 .699-705.2005$

[30] Murchison ND, Price BA, Conner DA, Keene DR, Olson EN, Tabin CJ, et al. Regulation of tendon differentiation by scleraxis distinguishes force-transmitting tendons from muscle-anchoring tendons. Development. 2007;134:2697-2708. DOI: 10.1242/dev.001933

[31] Meier Buergisser GM, Buschmann J. History and performance of implant materials applied as peritendinous antiadhesives. Journal of Biomedical Materials Research Part B-Applied Biomaterials. 2015;103:212-228. DOI: 10.1002/jbm.b.33182

[32] Bi Y, Ehirchiou D, Kilts TM, Inkson CA, Embree MC, Sonoyama W, et al. Identification of tendon stem/progenitor cells and the role of the extracellular matrix in their niche. Nature Medicine. 2007;13:1219-1227. DOI: 10.1038/nm1630

[33] Yin Z, Chen X, Chen JL, Ouyang HW. Stem cells for tendon tissue engineering and regeneration. Expert Opinion on Biological Therapy. 2010;10:689-700. DOI: 10.1517/147 12591003769824

[34] Yin Z, Chen X, Chen JL, Shen WL, TMH N, Gao L, et al. The regulation of tendon stem cell differentiation by the alignment of nanofibers. Biomaterials. 2009;31:2163-2175. DOI: 10.1016/j.biomaterials.2009.11.083

[35] Itoi E, Berglund LJ, Grabowski JJ, Schultz FM, Growney ES, Morrey BF, et al. Tensile properties of the supraspinatus tendon. Journal of Orthopaedic Research. 1995;13:578584. DOI: $10.1002 /$ jor.1100130413

[36] Wren TAL, Yerby SA, Beaupré GS, Carter DR. Mechanical properties of the human achilles tendon. Clinical Biomechanics. 2001;16:245-251. DOI: 10.1016/S0268-0033(00)00089-9 
[37] Lewis G, Shaw KM. Tensile properties of human tendo achillis: Effect of donor age and strain rate. The Journal of Foot and Ankle Surgery. 1997;36:435-445. DOI: 10.1016/S10672516(97)80096-8

[38] Chandrashekar N, Mansouri H, Slauterbeck J, Hashemi J. Sex-based differences in the tensile properties of the human anterior cruciate ligament. Journal of Biomechanics. 2006;39:2943-2950. DOI: 10.1016/j.jbiomech.2005.10.031

[39] Morrison SM, Dick TJ, Wakeling JM. Structural and mechanical properties of the human Achilles tendon: Sex and strength effects. Journal of Biomechanics. 2015;48(12):35303533. DOI: 10.1016/j.jbiomech.2015.06.009

[40] Grosset J-F, Breen L, Stewart CE, Burgess KE, Onambélé GL. Influence of exercise intensity on training-induced tendon mechanical properties changes in older individuals. Age (Dordrecht, Netherlands). 2014;36:9657. DOI: 10.1007/s11357-014-9657-9

[41] Dowling BA, Dart AJ, Hodgson DR, Rose RJ, Walsh WR. Recombinant equine growth hormone does not affect the in vitro biomechanical properties of equine superficial digital flexor tendon. Veterinary Surgery. 2002;31:325-330. DOI: 10.1053/jvet.2002.33591

[42] Chamberlain CS, Duenwald-Kuehl SE, Okotie G, Brounts SH, Baer GS, Vanderby R. Temporal healing in rat achilles tendon: Ultrasound correlations. Annals of Biomedical Engineering. 2013;41:477-487. DOI: 10.1007/s10439-012-0689-y

[43] Saber S, Zhang AY, Ki SH, Lindsey DP, Smith RL, Riboh J, et al. Flexor tendon tissue engineering: Bioreactor cyclic strain increases construct strength. Tissue Engineering Part A. 2010;16:2085-2090. DOI: 10.1089/ten.tea.2010.0032

[44] Crevier N, Pourcelot P, Denoix JM, Geiger D, Bortolussi C, Ribot X, et al. Segmental variations of in vitro mechanical properties in equine superficial digital flexor tendons. American Journal of Veterinary Research. 1996;57:1111-1117

[45] Nourissat G, Berenbaum F, Duprez D. Tendon injury: From biology to tendon repair. Nature Reviews Rheumatology. 2015;11:223-233. DOI: 10.1038/nrrheum.2015.26

[46] Dong CJ, Lv YG. Application of collagen scaffold in tissue engineering: Recent advances and new perspectives. Polymers. 2016;8. Article ID: 42 . DOI: 10.3390/polym 8020042

[47] Kumar VA, Caves JM, Haller CA, Dai E, Liu L, Grainger S, et al. Collagen-based substrates with tunable strength for soft tissue engineering. Biomaterials Science. 2013;1:1193-1202. DOI: 10.1039/C3BM60129C

[48] Barber FA, Herbert MA, Coons DA. Tendon augmentation grafts: Biomechanical failure loads and failure patterns. Arthroscopy: The Journal of Arthroscopic \& Related Surgery: Official Publication of the Arthroscopy Association of North America and the International Arthroscopy Association. 2006;22:534-538. DOI: 10.1016/j.arthro.2005.12.021

[49] Kato YP, Christiansen DL, Hahn RA, Shieh SJ, Goldstein JD, Silver FH, Mechanicalproperties of collagen-fibers-A comparison of reconstituted and rat tail tendon fibers. Biomaterials. 1989;10:38-41. DOI: 10.1016/0142-9612(89)90007-0 
[50] Zeugolis DI, Paul RG, Attenburrow G. Post-self-assembly experimentation on extruded collagen fibres for tissue engineering applications. Acta Biomaterialia. 2008;4:1646-1656. DOI: 10.1016/j.actbio.2008.05.015

[51] Zeugolis DI, Paul RG, Attenburrow G. Extruded collagen-polyethylene glycol fibers for tissue engineering applications. Journal of Biomedical Materials Research Part B-Applied Biomaterials. 2008;85B:343-352. DOI: 10.1002/jbm.b.30952

[52] Zeugolis DI, Paul GR, Attenburrow G. Cross-linking of extruded collagen fibers-A biomimetic three-dimensional scaffold for tissue engineering applications. Journal of Biomedical Materials Research Part A. 2009;89:895-908. DOI: 10.1002/jbm.a.32031

[53] Omenetto FG, Kaplan DL. New opportunities for an ancient material. Science. 2010; 329:528-531. DOI: 10.1126/science.1188936

[54] Hofmann S, Hilbe M, Fajardo RJ, Hagenmueller H, Nuss K, Arras M, et al. Remodeling of tissue-engineered bone structures in vivo. European Journal of Pharmaceutics and Biopharmaceutics. 2013;85:119-129. DOI: 10.1016/j.ejpb.2013.02.011

[55] Li X, Snedeker JG. Wired silk architectures provide a biomimetic ACL tissue engineering scaffold. Journal of the Mechanical Behavior of Biomedical Materials. 2013;22:30-40. DOI: 10.1016/j.jmbbm.2013.03.015

[56] Musson DS, Naot D, Chhana A, Matthews BG, McIntosh JD, Lin STC, et al. In vitro evaluation of a novel non-mulberry silk scaffold for use in tendon regeneration. Tissue Engineering Part A. 2015;21:1539-1551. DOI: 10.1089/ten.tea.2014.0128

[57] Tellado SF, Bonani W, Balmayor ER, Foehr P, Motta A, Migliaresi C, et al. Fabrication and characterization of biphasic silk fibroin scaffolds for tendon/ligament-to-bone tissue engineering. Tissue Engineering Part A. 2017;23:859-872. DOI: 10.1089/ten.tea.2016.0460

[58] Shen W, Chen X, Hu Y, Yin Z, Zhu T, Hu J, et al. Long-term effects of knitted silk-collagen sponge scaffold on anterior cruciate ligament reconstruction and osteoarthritis prevention. Biomaterials. 2014;35:8154-8163. DOI: 10.1016/j.biomaterials.2014.06.019

[59] Zheng ZF, Ran JS, Chen WS, Hu YJ, Zhu T, Chen X, et al. Alignment of collagen fiber in knitted silk scaffold for functional massive rotator cuff repair. Acta Biomaterialia. 2017;51:317-329. DOI: 10.1016/j.actbio.2017.01.041

[60] Stoppato M, Stevens HY, Carletti E, Migliaresi C, Motta A, Guldberg RE. Effects of silk fibroin fiber incorporation on mechanical properties, endothelial cell colonization and vascularization of PDLLA scaffolds. Biomaterials. 2013;34:4573-4581. DOI: 10.1016/j. biomaterials.2013.02.009

[61] Zhang W, Yang Y, Zhang K, Li Y, Fang G. Weft-knitted silk-poly(lactide-co-glycolide) mesh scaffold combined with collagen matrix and seeded with mesenchymal stem cells for rabbit Achilles tendon repair. Connective Tissue Research. 2015;56:25-34. DOI: 10.3109/03008207.2014.976309

[62] Sahoo S, Toh SL, Goh JCH. PLGA nanofiber-coated silk microfibrous scaffold for connective tissue engineering. Journal of Biomedical Materials Research Part B-Applied Biomaterials. 2010;95B:19-28. DOI: 10.1002/jbm.b.31678 
[63] Chen CH, Chen SH, Kuo CY, Li ML, Chen JP. Response of dermal fibroblasts to biochemical and physical cues in aligned polycaprolactone/silk fibroin nanofiber scaffolds for application in tendon tissue engineering. Nanomaterials. 2017;7. DOI: 10.3390/nano7080219

[64] Correia C, Bhumiratana S, Yan LP, Oliveira AL, Gimble JM, Rockwood D, et al. Development of silk-based scaffolds for tissue engineering of bone from human adiposederived stem cells. Acta Biomaterialia. 2012;8:2483-2492. DOI: 10.1016/j.actbio.2012.03.019

[65] Woloszyk A, Buschmann J, Waschkies C, Stadlinger B, Mitsiadis T. Human dental pulp stem cells and gingival fibroblasts seeded into silk fibroin scaffolds have the same ability in attracting vessels. Frontiers in Physiology. 2016. Article ID: 140. DOI: 10.3389/ fphys.2016.00140

[66] Woloszyk A, Holsten Dircksen S, Bostanci N, Müller R, Hofmann S, Mitsiadis TA. Influence of the mechanical environment on the engineering of mineralised tissues using human dental pulp stem cells and silk fibroin scaffolds. PLoS One. 2014;9:e111010. DOI: 10.1371/journal.pone.0111010

[67] Fuchs S, Jiang X, Schmidt H, Dohle E, Ghanaati S, Orth C, et al. Dynamic processes involved in the pre-vascularization of silk fibroin constructs for bone regeneration using outgrowth endothelial cells. Biomaterials. 2009;30:1329-1338. DOI: 10.1016/j.biomaterials.2008.11.028

[68] Islam S, Bhuiyan MAR, Islam MN. Chitin and chitosan: Structure, properties and applications in biomedical engineering. Journal of Polymers and the Environment. 2017;25:854866. DOI: 10.1007/s10924-016-0865-5

[69] Nowotny J, Aibibu D, Farack J, Nimtschke U, Hild M, Gelinsky M, et al. Novel fiberbased pure chitosan scaffold for tendon augmentation: Biomechanical and cell biological evaluation. Journal of Biomaterials Science-Polymer Edition. 2016;27:917-936. DOI: 10.1080/09205063.2016.1155879

[70] Gates SJ, Shukla A. Layer-by-layer assembly of readily detachable chitosan and poly (acrylic acid) polyelectrolyte multilayer films. Journal of Polymer Science Part B-Polymer Physics. 2017;55:127-131. DOI: 10.1002/polb.24234

[71] Funakoshi T, Majima T, Iwasaki N, Suenaga N, Sawaguchi N, Shimode K, et al. Application of tissue engineering techniques for rotator cuff regeneration using a chitosan-based hyaluronan hybrid fiber scaffold. The American Journal of Sports Medicine. 2005;33:11931201. DOI: $10.1177 / 0363546504272689$

[72] Irie T, Majima T, Sawaguchi N, Funakoshi T, Nishimura S, Minami A. Biomechanical and histologic evaluation of tissue engineered ligaments using chitosan and hyaluronan hybrid polymer fibers: A rabbit medial collateral ligament reconstruction model. Journal of Biomedical Materials Research Part A. 2011;97A:111-117. DOI: 10.1002/jbm.a.32938

[73] Raftery RM, Woods B, Marques ALP, Moreira-Silva J, Silva TH, Cryan SA, et al. Multifunctional biomaterials from the sea: Assessing the effects of chitosan incorporation into collagen scaffolds on mechanical and biological functionality. Acta Biomaterialia. 2016;43:160-169. DOI: 10.1016/j.actbio.2016.07.009 
[74] Yang Z, Cao H, Gao S, Yang M, Lyu J, Tang K. Effect of tendon stem cells in chitosan/ beta-glycerophosphate/collagen hydrogel on Achilles tendon healing in a rat model. Medical Science Monitor: International Medical Journal of Experimental and Clinical Research. 2017;23:4633-4643

[75] Ratner BD. A pore way to heal and regenerate: 21st century thinking on biocompatibility. Regenerative Biomaterials. 2016;3:107-110. DOI: 10.1093/rb/rbw006

[76] Mantovani A. Macrophage diversity and polarization: In vivo veritas. Blood. 2006;108: 408-409. DOI: 10.1182/blood-2006-05-019430

[77] Cao D, Liu W, Wei X, Xu F, Cui L, Cao Y. In vitro tendon engineering with avian tenocytes and polyglycolic acids: A preliminary report. Tissue Engineering. 2006;12:13691377. DOI: $10.1089 /$ ten.2006.12.1369

[78] Ouyang HW, Goh JCH, Thambyah A, Teoh SH, Lee EH. Knitted poly-lactide-co-glycolide scaffold loaded with bone marrow stromal cells in repair and regeneration of rabbit Achilles tendon. Tissue Engineering. 2003;9:431-439

[79] Surrao DC, Waldman SD, Amsden BG. Biomimetic poly(lactide) based fibrous scaffolds for ligament tissue engineering. Acta Biomaterialia. 2012;8:3997-4006. DOI: 10.1016/j. actbio.2012.07.012

[80] Liu W, Lipner J, Moran CH, Feng L, Li X, Thomopoulos S, et al. Generation of electrospun nanofibers with controllable degrees of crimping through a simple, plasticizer-based treatment. Advanced Materials. 2015;27:2583-2588

[81] MacGillivray JD, Fealy S, Terry MA, Koh JL, Nixon AJ, Warren RF. Biomechanical evaluation of a rotator cuff defect model augmented with a bioresorbable scaffold in goats. Journal of Shoulder and Elbow Surgery/American Shoulder and Elbow Surgeons. 2006; 15:639-644. DOI: 10.1016/j.jse.2005.11.009

[82] Madhavarapu S, Rao R, Libring S, Fleisher E, Yankannah Y, Freeman JW. Design and characterization of three-dimensional twist-braid scaffolds for anterior cruciate ligament regeneration. Technology. 2017;5:98-106. DOI: 10.1142/s2339547817500066

[83] Zhang C, Wang X, Zhang E, Yang L, Yuan H, Tu W, et al. An epigenetic bioactive composite scaffold with well-aligned nanofibers for functional tendon tissue engineering. Acta Biomaterialia. 2017;66:141-156. DOI: 10.1016/j.actbio.2017.09.036

[84] Freeman JW, Woods MD, Laurencin CT. Tissue engineering of the anterior cruciate ligament using a braid-twist scaffold design. Journal of Biomechanics. 2007;40:2029-2036. DOI: 10.1016/j.jbiomech.2006.09.025

[85] Liu S, Zhao J, Ruan H, Tang T, Liu G, Yu D, et al. Biomimetic sheath membrane via electrospinning for antiadhesion of repaired tendon. Biomacromolecules. 2012;13:3611-3619. DOI: $10.1021 / \mathrm{bm} 301022 \mathrm{p}$

[86] Santoni BG, McGilvray KC, Lyons AS, Bansal M, Turner AS, Macgillivray JD, et al. Biomechanical analysis of an ovine rotator cuff repair via porous patch augmentation 
in a chronic rupture model. The American Journal of Sports Medicine. 2010;38:679-686. DOI: $10.1177 / 0363546510366866$

[87] Marx RG, Koulouvaris P, Chu SK, Levy BA. Indications for surgery in clinical outcome studies of rotator cuff repair. Clinical Orthopaedics and Related Research. 2009;467:450456. DOI: 10.1007/s11999-008-0585-9

[88] Seitz H, Pichl W, Matzi V, Nau T. Biomechanical evaluation of augmented and nonaugmented primary repair of the anterior cruciate ligament: An in vivo animal study. International Orthopaedics. 2013;37(11):2305. DOI: 10.1007/s00264-013-2098-8

[89] Li H, Jiang J, Ge Y, Xu J, Zhang P, Zhong W, et al. Layer-by-layer hyaluronic acid-chitosan coating promoted new collagen ingrowth into a poly(ethylene terephthalate) artificial ligament in a rabbit medical collateral ligament (MCL) reconstruction model. Journal of BiomaterialsScience.PolymerEdition.2013;24:431-446.DOI:10.1080/09205063.2012.690284

[90] Buschmann J, Calcagni M, Meier Buergisser G, Bonavoglia E, Neuenschwander P, Milleret $\mathrm{V}$, et al. Synthesis, characterization and histomorphometric analysis of cellular response to a new elastic DegraPol (R) polymer for rabbit Achilles tendon rupture repair. Journal of Tissue Engineering and Regenerative Medicine. 2015;9:584-594. DOI: 10.1002/term.1624

[91] Buschmann J, Meier Buergisser G, Bonavoglia E, Neuenschwander P, Milleret V, Giovanoli $\mathrm{P}$, et al. Cellular response of healing tissue to DegraPol tube implantation in rabbit Achilles tendon rupture repair: An in vivo histomorphometric study. Journal of Tissue Engineering and Regenerative Medicine. 2013;7:413-420. DOI: 10.1002/term.538

[92] Green EC, Zhang YY, Li H, Minus ML. Gel-spinning of mimetic collagen and collagen/nano-carbon fibers: Understanding multi-scale influences onmolecular ordering and fibril alignment. Journal of the Mechanical Behavior of Biomedical Materials. 2017;65:552-564. DOI: 10.1016/j.jmbbm.2016.08.022

[93] Sears NA, Pena-Galea G, Cereceres SN, Cosgriff-Hernandez E. Hybrid polyurea elastomers with enzymatic degradation and tunable mechanical properties. Journal of Tissue Engineering. 2016;7:1-7. DOI: 10.1177/2041731416679363

[94] Hess SC, Stark WJ, Mohn D, Cohrs NH, Märsmann S, Calcagni M, et al. Gene expression in human adipose-derived stem cells: Comparison of 2D films, 3D electrospun meshes or co-cultured scaffolds with two-way paracrine effects. European Cells \& Materials. 2017;34:232-248

[95] Bohac M, Csobonyeiova M, Kupcova I, Zamborsky R, Fedele J, Koller J. Stem cell regenerative potential for plastic and reconstructive surgery. Cell and Tissue Banking. 2016;17:735-744. DOI: 10.1007/s10561-016-9583-4

[96] Qiu YW, Wang X, Zhang YN, Carr AJ, Zhu LW, Xia ZD, et al. In vitro two-dimensional and three-dimensional tenocyte culture for tendon tissue engineering. Journal of Tissue Engineering and Regenerative Medicine. 2016;10:E216-EE26. DOI: 10.1002/term.1791

[97] Deng D, Liu W, Xu F, Yang Y, Zhou G, Zhang WJ, et al. Engineering human neo-tendon tissue in vitro with human dermal fibroblasts under static mechanical strain. Biomaterials. 2009;30:6724-6730. DOI: 10.1016/j.biomaterials.2009.08.054 
[98] Zuk PA, Zhu M, Mizuno H, Huang J, Futrell JW, Katz AJ, et al. Multilineage cells from human adipose tissue: Implications for cell-based therapies. Tissue Engineering. 2001;7:211-228. DOI: 10.1089/107632701300062859

[99] Buschmann J, Gao S, Härter L, Hemmi S, Welti M, Werner CML, et al. Yield and proliferation rate of adipose-derived stem cells as a function of age, BMI and harvest site: Increasing the yield by using adherent and supernatant fractions? Cytotherapy. 2013;15:1098-1105. DOI: 10.1016/j.jcyt.2013.04.009

[100] Long C, Wang Z, Legrand A, Chattopadhyay A, Chang J, Fox PM. Tendon tissue engineering: Mechanism and effects of human tenocyte coculture with adipose-derived stem cells. The Journal of Hand Surgery. 2017;S0363-5023(17)31322-31329. DOI: 10.1016/j.jhsa.2017.07.031

[101] Wu S, Wang Y, Streubel PN, Duan B. Living nanofiber yarn-based woven biotextiles for tendon tissue engineering using cell tri-culture and mechanical stimulation. Acta Biomaterialia. 2017;62:102-115. DOI: 10.1016/j.actbio.2017.08.043

[102] Butler DL, Hunter SA, Chokalingam K, Cordray MJ, Shearn J, Juncosa-Melvin N, et al. Using functional tissue engineering and bioreactors to mechanically stimulate tissue-engineered constructs. Tissue Engineering Part A. 2009;15:741-749. DOI: 10.1089/ten.tea.2008.0292

[103] Nirmalanandhan VS, Dressler MR, Shearn JT, Juncosa-Melvin N, Rao M, Gooch C, et al. Mechanical stimulation of tissue engineered tendon constructs: Effect of scaffold materials. Journal of Biomechanical Engineering. 2007;129:919-923. DOI: 10.1115/1.2800828

[104] Chokalingam K, Juncosa-Melvin N, Hunter SA, Gooch C, Frede C, Florert J, et al. Tensile stimulation of murine stem cell-collagen sponge constructs increases collagen type I gene expression and linear stiffness. Tissue Engineering Part A. 2009;15:25612570. DOI: 10.1089/ten.TEA.2008.0451

[105] Thorfinn J, Angelidis IK, Gigliello L, Pham HM, Lindsey D, Chang J. Bioreactor optimization of tissue engineered rabbit flexor tendons in vivo. The Journal of Hand Surgery, European Volume. 2012;37:109-114. DOI: 10.1177/1753193411419439

[106] Wang T, Gardiner BS, Lin Z, Rubenson J, Kirk TB, Wang A, et al. Bioreactor design for tendon/ligament engineering. Tissue Engineering Part B-Reviews. 2013;19:133-146. DOI: $10.1089 /$ ten.teb.2012.0295

[107] Mace J, Wheelton A, Khan WS, Anand S. The role of bioreactors in ligament and tendon tissue engineering. Current Stem Cell Research \& Therapy. 2016;11:35-40. DOI: 10.2174/ $1574888 \times 10666150904113827$

[108] Youngstrom DW, Barrett JG. Engineering tendon: Scaffolds, bioreactors, and models of regeneration. Stem Cells International. 2016. Article ID: 3919030. DOI: $10.1155 / 2016 / 3919030$

[109] Roth SP, Glauche SM, Plenge A, Erbe I, Heller S, Burk J. Automated freeze-thaw cycles for decellularization of tendon tissue-A pilot study. BMC Biotechnology. 2017;17(1): 1-13. DOI: 10.1186/s12896-017-0329-6 
[110] Bottagisio M, Pellegata AF, Boschetti F, Ferroni M, Moretti M, Lovati AB. A new strategy for the decellularization of large equine tendons as biocompatible tendon substitutes. European Cells \& Materials. 2016;32:58-73. DOI: 10.22203/eCM.v032a04

[111] Jakus AE, Laronda MM, Rashedi AS, Robinson CM, Lee C, Jordan SW, et al. "Tissue papers" from organ-specific decellularized extracellular matrices. Advanced Functional Materials. 2017;27. Article ID: 1700992. DOI: 10.1002/adfm.201700992

[112] Hoshiba T, Kawazoe N, Chen GP. The balance of osteogenic and adipogenic differentiation in human mesenchymal stem cells by matrices that mimic stepwise tissue development. Biomaterials. 2012;33:2025-2031. DOI: 10.1016/j.biomaterials.2011.11.061

[113] Claudio-Rizo JA, Rangel-Argote M, Castellano LE, Delgado J, Mata-Mata JL, MendozaNovelo B. Influence of residual composition on the structure and properties of extracellular matrix derived hydrogels. Materials Science \& Engineering C-Materials for Biological Applications. 2017;79:793-801. DOI: 10.1016/j.msec.2017.05.118

[114] Parmaksiz M, Dogan A, Odabas S, Elcin AE, Elcin YM. Clinical applications of decellularized extracellular matrices for tissue engineering and regenerative medicine. Biomedical Materials. 2016;11. DOI: 10.1088/1748-6041/11/2/022003

[115] Tang JB, Zhou YL, Wu YF, Liu PY, Wang XT. Gene therapy strategies to improve strength and quality of flexor tendon healing. Expert Opinion on Biological Therapy. 2016;16:291-301. DOI: 10.1517/14712598.2016.1134479

[116] Chien C, Pryce B, Tufa SF, Keene DR, Huang AH. Optimizing a 3D model system for molecular manipulation of tenogenesis. Connective Tissue Research. 2017. DOI: 10.1080/03008207.2017.1383403. http://www.tandfonline.com/loi/icts20

[117] Basile P, Dadali T, Jacobson J, Hasslund S, Ulrich-Vinther M, Soballe K, et al. Freezedried tendon allografts as tissue-engineering scaffolds for gdf5 gene delivery. Molecular Therapy. 2008;16:466-473. DOI: 10.1038/sj.mt.6300395

[118] Martinek V, Latterman C, Usas A, Abramowitch S, Woo SLY, Fu FH, et al. Enhancement of tendon-bone integration of anterior cruciate ligament grafts with bone morphogenetic protein-2 gene transfer-A histological and biomechanical study. Journal of Bone and Joint Surgery-American Volume. 2002;84A:1123-1131

[119] Wu YF, Mao WF, Zhou YL, Wang XT, Liu PY, Tang JB. Adeno-associated virus-2-mediated TGF-beta 1 microRNA transfection inhibits adhesion formation after digital flexor tendon injury. Gene Therapy. 2016;23:167-175. DOI: 10.1038/gt.2015.97

[120] Tang JB, Wu YF, Cao Y, Chen CH, Zhou YL, Avanessian B, et al. Basic FGF or VEGF gene therapy corrects insufficiency in the intrinsic healing capacity of tendons. Scientific Reports. 2016;6. Article ID: 20643. DOI: 10.1038/srep20643

[121] Abbah SA, Thomas D, Browne S, O'Brien T, Pandit A, Zeugolis DI. Co-transfection of decorin and interleukin-10 modulates pro-fibrotic extracellular matrix gene expression in human tenocyte culture. Scientific Reports. 2016;6. Article ID: 20992. DOI: 10.1038/ srep20922 
[122] Mao WF, Wu YF, Yang QQ, Zhou YL, Wang XT, Liu PY, et al. Modulation of digital flexor tendon healing by vascular endothelial growth factor gene transfection in a chicken model. Gene Therapy. 2017;24(9):234-240. Article ID: 20992. DOI: 10.1038/gt.2017.12

[123] Tan C, Lui PPY, Lee YW, Wong YM. Scx-transduced tendon-derived stem cells (TDSCs) promoted better tendon repair compared to mock-transduced cells in a rat patellar tendon window injury model. PLoS One. 2014;9:e97453. DOI: 10.1371/journal.pone.0097453

[124] Kawakami Y, Takayama K, Matsumoto T, Tang Y, Wang B, Mifune Y, et al. Anterior cruciate ligament-derived stem cells transduced with BMP2 accelerate graft-bone integration after ACL reconstruction. The American Journal of Sports Medicine. 2017;45:584-597. DOI: $10.1177 / 0363546516671707$

[125] Evrova O, Buschmann J. In vitro and in vivo effects of PDGF-BB delivery strategies on tendon healing: A review. European Cells \& Materials. 2017;34:15-39. DOI: 10.22203/ eCM.v034a02

[126] Meier Buergisser G, Calcagni M, Muller A, Bonavoglia E, Fessel G, Snedeker JG, et al. Prevention of peritendinous adhesions using an electrospun DegraPol polymer tube: A histological, ultrasonographic, and biomechanical study in rabbits. BioMed Research International. 2014;2014:656240. DOI: 10.1155/2014/656240 
